\title{
Distinct gene regulatory signatures of dominance rank and social bond
} strength in wild baboons

Jordan A. Anderson ${ }^{1}$, Amanda J. Lea ${ }^{2,3,4}$, Tawni N. Voyles ${ }^{1}$, Mercy Y. Akinyi ${ }^{5}$, Ruth Nyakundi ${ }^{5}$, Lucy Ochola ${ }^{5}$, Martin Omondi ${ }^{5}$, Fred Nyundo ${ }^{5}$, Yingying Zhang ${ }^{1}$, Fernando A. Campos ${ }^{6}$, Susan C. Alberts ${ }^{1,2}$, Elizabeth A. Archie ${ }^{7}$, and Jenny Tung ${ }^{1,2,8,9}$

${ }^{1}$ Department of Evolutionary Anthropology, Duke University, Durham, North Carolina 27708, USA

2Department of Biology, Duke University, Durham, North Carolina 27708, USA

${ }^{3}$ Lewis-Sigler Institute for Integrative Genomics, Carl Icahn Laboratory, Princeton University, Princeton, NJ 08544, USA ${ }^{4}$ Department of Ecology and Evolution, Princeton University, Princeton, NJ 08544, USA ${ }^{5}$ Institute of Primate Research, National Museums of Kenya, Nairobi 00502, Kenya ${ }^{6}$ Department of Anthropology, University of Texas at San Antonio, San Antonio, TX 78249, USA ${ }^{7}$ Department of Biological Sciences, University of Notre Dame, Notre Dame, Indiana 46556, USA

${ }^{8}$ Duke Population Research Institute, Duke University, Durham, NC 27708, USA

${ }^{9}$ Canadian Institute for Advanced Research, Toronto, Canada M5G 1M1, Canada

*Correspondence: it5@duke.edu

\section{Abstract:}

The social environment is a major determinant of morbidity, mortality, and Darwinian fitness in social animals. Recent studies have begun to uncover the molecular processes associated with these relationships, but the degree to which they vary across different dimensions of the social environment remains unclear. Here, we draw on a long-term field study of wild baboons to compare the signatures of affiliative and competitive aspects of the social environment in white blood cell gene regulation, under both immune stimulated and nonstimulated conditions. We find that the effects of dominance rank on gene expression are directionally opposite in males versus females, such that high-ranking males resemble lowranking females, and vice-versa. Among females, rank and social bond strength are both reflected in the activity of cellular metabolism and proliferation genes. However, pronounced rank-related differences in baseline immune gene activity are near-absent for social bond strength, while only bond strength predicts the fold-change response to immune (lipopolysaccharide) stimulation. Together, our results indicate that the directionality and magnitude of social effects on gene regulation depend on the aspect of the social environment under study. This heterogeneity may help explain why social environmental effects on health and longevity can also vary between measures. 


\section{INTRODUCTION}

Many animal species, including humans, live the majority of their lives as part of a larger group of conspecifics. Social group living provides a number of benefits, including protection from predators, improved territory and resource defense, and access to potential mates [1-4]. At the same time, it also generates competition for resources among group members. For many group-living species, the outcome of competitive interactions is at least partially predictable, giving rise to an observable social dominance hierarchy in which high status animals are consistently able to displace lower status animals [5-7]. Due to correlated differences in resource access, energy expenditure, and/or psychosocial stress, high-ranking and low-ranking animals are frequently behaviorally and physiologically distinct. For example, across social mammals, low status individuals often have elevated glucocorticoid levels or exhibit signs of glucocorticoid resistance [8-12].

However, correlations between social status and physiological measures are highly heterogeneous across species or between sexes, and sometimes even directionally inconsistent [8,13-18]. This heterogeneity is likely explained in part by differences in how status is attained and maintained. In some cases social status depends on individual characteristics, such as the ability to physically dominate competitors (e.g., male bottlenose dolphins, male red deer, female meerkats: [19-21]). In contrast, other types of social hierarchies are determined via nepotism, and do not strongly covary with individual phenotype (e.g., female spotted hyenas, some female cercopithecine primates: $[22,23])$. Hierarchies that are largely determined by physical condition are often dynamic, whereas nepotistic hierarchies can remain highly stable over time, and even extend across generations [24-26]. Consequently, while rank is an important predictor of fitness in both types of hierarchies [27-31], its physiological signatures may differ. For example, while high rank predicts lower glucocorticoid levels in female blue monkeys, female baboons, and naked mole-rats of both sexes [10,13,32,33], glucocorticoid levels tend to be higher in high rank female ring-tailed lemurs, female meerkats, and male chimpanzees $[18,34,35]$.

In addition to the competitive interactions that structure social hierarchies, group-living animals can also form individually differentiated, affiliative social bonds. The affiliative behaviors that give rise to social bonds (e.g., proximity or contact in cetaceans and ungulates, grooming and proximity in primates) are often patterned, at least in part, by social status [36-42]. For example, in cooperatively breeding meerkats, dominant males groom dominant females more often than they groom subordinate females [43]. Similarly, attraction to high-ranking individuals commonly structures grooming patterns in social primates [40]. However, rank is not the sole determinant of affiliative behavior and social bond formation. In female yellow baboons, for instance, a measure of female social connectedness to other females is better predicted by the presence of maternal kin than by rank (although rank, not the presence of maternal kin, predicts female social connectedness to males; [44]). Recent evidence also indicates that the fitness effects of affiliative social relationships are also partially independent of rank. Stronger social relationships predict natural lifespan in members of at least five mammalian orders, and this relationship often persists after controlling for variation in rank or other measures of social status [38,45-51]. Indeed, in yellow baboons, social relationships predict lifespan even when rank does not [45]. 
Social status and social integration are therefore connected dimensions of the social environment that nevertheless can have distinct fitness consequences. This observation presents a puzzle about the mechanisms that make their consequences for health, physiology, and survival distinct. To date, far more work has focused on the physiological and molecular correlates of social status than of affiliative social bonds in natural animal populations. However, four lines of evidence argue that differences in affiliative social interactions should also be reflected in physiological or molecular variation. First, such changes are implied by cross-taxon support for an association between lifespan and social integration [52], suggesting at least a partial basis in physical condition. Second, studies in a small set of natural populations have already identified links between affiliative relationships and biomarkers of stress, especially glucocorticoid levels. For example, urinary glucocorticoids are lower in chimpanzees sampled while interacting with closely bonded social partners than in those interacting with non-bonded partners [53], and male rhesus macaques and female chacma baboons with stronger social bonds show reduced glucocorticoid responses to environmental stressors [54-56]. Third, social isolation and loneliness are associated with changes in human biology, including increased proinflammatory activity [57-59], hypothalamic-pituitary-adrenal axis activation [60,61], and risk for cardiovascular disease $[62,63]$. Finally, studies in captive rodents show that manipulation of social integration and social support can causally alter glucocorticoid regulation and increase the risk of cancer metastasis $[64,65]$.

Despite these findings, most studies consider either the physiological signature of social status or of affiliative social relationships, not both. Further, those studies that incorporate both dimensions often measure only a single outcome variable in one type of social status hierarchy (i.e., physical competition-based or nepotistic). Because single measures vary along only one dimension, they have limited ability to distinguish shared versus unique signatures of competitive and affiliative interactions. Thus, it is possible that physiological changes in response to the social environment converge on a generalized signature of stress and adversity, in which low status and weak social bonds produce undifferentiable responses (e.g., the "conserved transcriptional response to adversity": [66]). Alternatively, different facets of the social environment may be reflected in different biological pathways. If so, higher dimensional measures of physiological or molecular state may be informative about multiple aspects of an animal's social experience, and help uncover why social status and social affiliation can be related, yet have distinct effects on fitness.

Functional genomic analyses of gene regulation provide an opportunity to differentiate these hypotheses. Importantly, previous work demonstrates the sensitivity of gene regulation to the social environment. For example, competitive interactions to establish dominance rapidly alter DNA methylation, histone marks, and gene expression across multiple vertebrate and social insect species [67-73]. Affiliative interactions can also be reflected in altered gene expression patterns. For example, experimental social isolation in piglets results in increased plasma cortisol and altered glucocorticoid and mineralocorticoid receptor expression in stressrelated regions of the brain [74]. However, the species that have been central to understanding the genomic signatures of social status and social competition (e.g., cichlid fish, mice) tend not to be the same ones developed as models for social affiliation (e.g., voles, titi monkeys). Additionally, few studies of social interactions and gene regulation have focused on species that 
establish both clear social dominance hierarchies and long-term social bonds outside the mating pair-bond.

To begin addressing this gap, this study draws on data and samples from a five decadelong field study of wild baboons in Kenya, in which the fitness consequences of both social status and social relationships have been extensively investigated in prior work $[29,44,45,75-$ 78]. Gene regulatory signatures of the social environment have also been detected in this population $[15,79]$. Most relevant to this work, high-ranking baboon males exhibit elevated expression of inflammation-related genes both at baseline and upon stimulation with lipopolysaccharide (LPS; a pathogen-associated molecular pattern associated with gramnegative bacteria, and a strong driver of the innate inflammatory response: [15]). In contrast, little signature of rank was detectable in females [15]. This result is consistent with findings that high rank in males (but not females) predicts accelerated epigenetic aging, elevated glucocorticoid and testosterone levels, and, to a lesser extent, higher mortality rates $[14,45,80]$. However, it contrasts with the hypothesis of a highly consistent gene regulatory response to the social environment [66].

Together, these observations raise key questions about the extent to which the links between social experience and gene regulation are sex- and/or context-specific. To address them here, we expand on our previous white blood cell gene expression data sets by $64 \%$ (from $\mathrm{n}=119$ to $\mathrm{n}=195$ samples, including paired baseline and LPS-stimulated samples from nearly all individuals; Table S1). We also generated ATAC-seq data on chromatin accessibility in baseline and LPS-stimulated samples to infer the transcription factor binding events that explain social environment associations with gene expression. Our results indicate even more substantial sex differences in the signature of dominance rank than was apparent in previous work. We also identify, for the first time in any natural vertebrate population, a strong signal of social bond strength on gene regulation. Although several of the major pathways associated with rank and social bond strength overlap, their signatures are clearly distinct, and only social bond strength predicts the gene expression response to pathogen stimulation (i.e., the difference between baseline and LPS-stimulated cells from the same individual). Together, this work emphasizes the strong relationship between the social environment and gene regulation in the immune system in wild social mammals. It thus deepens our understanding of how fitnessrelevant social experiences "get under the skin" to affect health and fitness outcomes.

\section{RESULTS}

\section{Directionally opposite gene expression signatures of dominance rank in male and female baboons}

We used RNA-seq to measure genome-wide gene expression levels in white blood cells from 97 unique adult baboons (45 females, 52 males; Table S1). For each animal, we collected RNA from paired baseline (unstimulated cells cultured in media) and LPS-stimulated samples that were cultured in parallel for 10 hours (Fig 1A; following [15]). Following quality control, our data set consisted of RNA-seq data from 195 samples (119 samples from previously published work and an additional 76 samples that are newly reported here; 97 unique individuals total, with 3 individuals represented by more than one blood draw; Table S1). Samples were sequenced to a mean coverage of 17.4 million reads \pm 7.7 million s.d. (Table S1). After filtering 
171 for genes that were detectably expressed in one or both conditions (median RPKM > 2 in either 172 condition), we retained 10,281 genes for downstream analysis.

173 We first investigated the signature of dominance rank separately in each sex. Consistent

174 with our earlier work [15], we found widespread associations between male ordinal dominance

175 rank and gene expression levels. 2,345 genes were significantly associated with male rank in

176 baseline samples and 2,996 in LPS-stimulated samples (22.8\% and $29.1 \%$ of genes tested,

177 respectively; i.e., $\beta_{\text {rank }} \neq 0$ in a linear mixed effects model controlling for technical covariates,

178 age, and treatment effects, 10\% FDR; Table S2. An elastic net model relating gene expression

179 to dominance rank thus predicted male rank with moderately high accuracy (Pearson's

$180 \mathrm{R}=0.449, \mathrm{p}=8.46 \times 10^{-4}$; Fig 1B; Fig S1). In females, gene expression data were also significant 181 predictors of dominance rank (Pearson's $\mathrm{R}=0.656, p=1.31 \times 10^{-6}$; Fig 1C; Table S3). However, 182 the elastic net analysis for females revealed one female (AMB_2) who was high-ranking at the

183 time of sampling (ordinal rank 3) but was predicted to be very low-ranking in both baseline and 184 LPS samples (predicted ordinal rank 17.7 and 19.4, respectively; Fig S1). By substantially 185 increasing our sample size and excluding AMB_2, we were able to identify female dominance 186 rank-gene expression associations that were undetectable in previous work [15], including 1,285 187 rank-associated genes at baseline and 221 rank-associated genes after LPS stimulation (12.5\% 188 and $2.1 \%$ of genes tested, respectively; $10 \%$ FDR; Table S2). Because AMB_2 was a clear 189 outlier in our sample, we report analyses excluding her in the remainder of our results; however, 190 our comparisons are qualitatively unchanged if AMB_2 is included (Fig S2). 
A

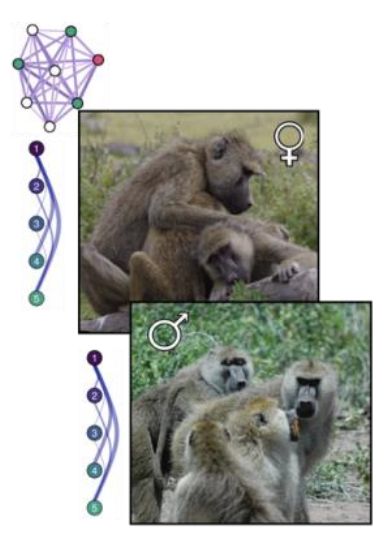

B

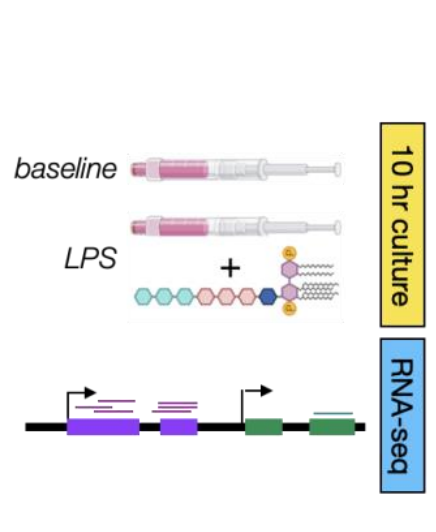

D $\left.\right|^{\substack{\text { higher expression low rank } \\ 5.0}}$

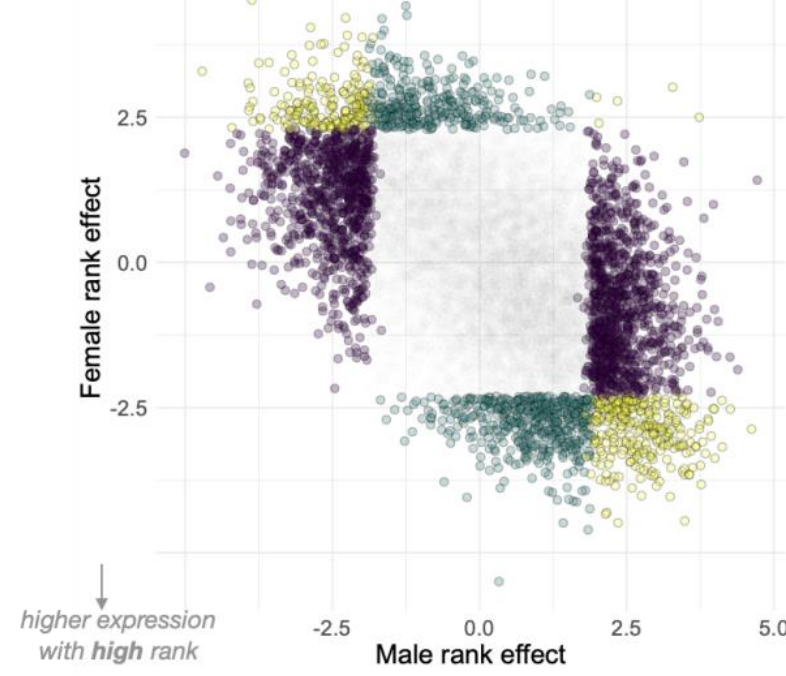

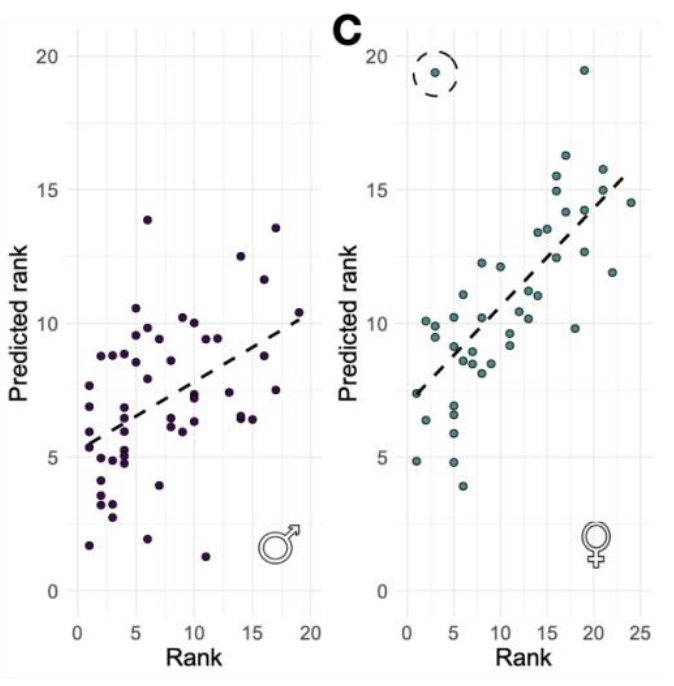
with high rank higher expression
E

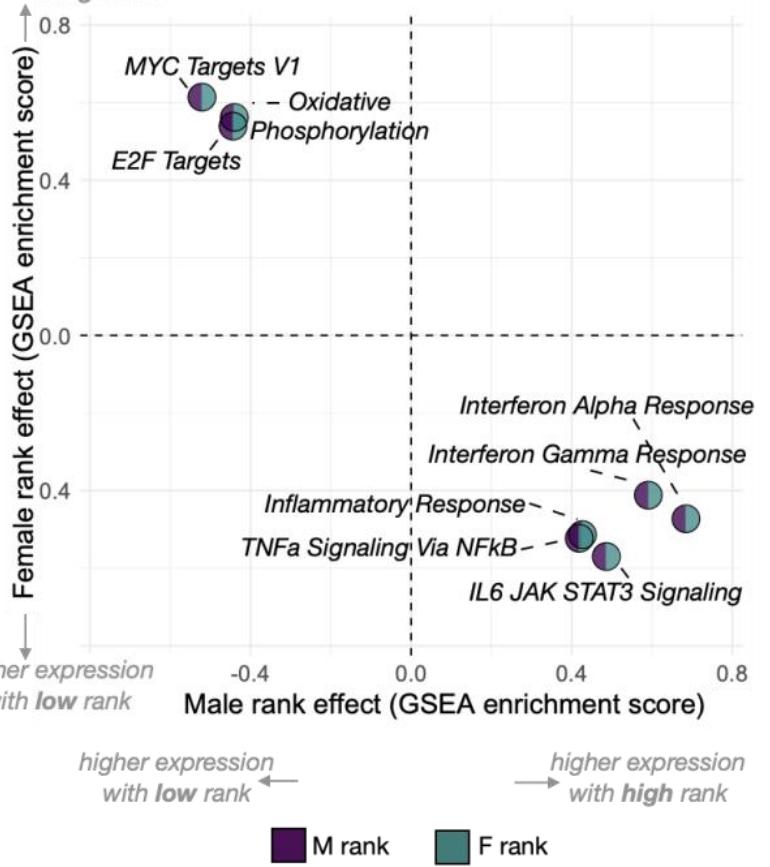

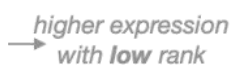

higher expression
$\longrightarrow$ with low rank

Figure 1. Strong, sex-specific signatures of dominance rank in white blood cell gene expression. (A) Study design: dominance rank (males and females) and social bond strength (females only) were evaluated for their relationship with white blood cell gene expression, generated from samples cultured for 10 hours in the absence (baseline) or presence of lipopolysaccharide (LPS). (B-C) A gene expression-based elastic net model accurately predicts dominance rank for male ( $B$; Pearson's $\left.R=0.449, p=8.46 \times 10^{-4}\right)$ and female ( $C$; Pearson's $R=0.656, p=1.31$ $\left.x 10^{-6}\right)$ baboons. (D) The effect estimates for the rank-gene expression association are negatively correlated in males versus females (Pearson's $\mathrm{R}=-0.544, \mathrm{p}<10^{-50}$; colored dots are genes that pass a $10 \%$ false discovery rate threshold). (E) Gene sets enriched for higher expression in high-ranking males are enriched for lower expression in high-ranking females, and vice-versa. Enrichment in males is shown in purple; enrichment in females is shown in green. For all gene sets, enrichment score Bonferroni-corrected $p$-values are $<0.005$. Photo credits in (A): Elizabeth Archie (females) and Courtney Fitzpatrick (males). Stock images of LPS and blood draw tubes courtesy of BioRender.com. 
In both males and females, the second principal component (PC2) of the overall gene expression data was correlated with rank (males: $p=1.68 \times 10^{-4}$; females: $p=0.013$; note that PC1 splits baseline from LPS-stimulated cells). However, while high-ranking males tended to project onto positive values of PC2, high-ranking females tended to project onto negative values (Fig S3). Effect size estimates for individual genes were also anti-correlated by sex, such that genes that were more highly expressed in high-ranking females tended to be more lowly expressed in high-ranking males (Pearson's $\mathrm{R}=-0.537, \mathrm{p}<10^{-50}$; Fig 1D; Fig S4). As a result, genes with increased activity in high-ranking males and low-ranking females were both enriched for inflammatory and type I interferon pathways (all $p_{\text {adj }}<0.005$; Fig 1E; Table S4) [81]. Meanwhile, genes with increased activity in low-ranking males and high-ranking females were both enriched for key metabolic and cell cycle-related pathways, including oxidative phosphorylation and myc signaling (all $p_{a d j}<0.005$; Table S4). Thus, the same genes and pathways were sensitive to rank dynamics in males and females, but in opposing directions. Indeed, when applying the predictive model trained for male rank to gene expression data from females, the model predictions were negatively correlated with the observed female ranks (Pearson's $\mathrm{R}=-0.339 ; \mathrm{p}=0.023$ ), and vice-versa (correlation between female-trained model predictions and observed male rank: Pearson's $R=-0.339, p=0.014)$. Similarly, accessible binding sites for immune response-related transcription factors (e.g., ISL1, KLF3, defined based on increased chromatin accessibility after LPS stimulation: see SI Methods; Tables S5-S6) were over-represented near genes upregulated in high-ranking males and near genes upregulated in low-ranking females (all $p<0.05$; Fig S6; Table S7).

\section{Distinct signatures of dominance rank and social bond strength in female baboons}

To investigate whether genes that are sensitive to dominance rank (regardless of effect direction) also carry a signature of other aspects of the social environment, we next assessed the relationship between social bond strength and gene expression in the same sample. We focused exclusively on females ( $n=88$ samples from $n=44$ unique individuals), using the "dyadic sociality index" (DSI), a strong predictor of lifespan in our study population that captures an annual measure of the strength of a female's bonds with her top three female partners [45]. Female-to-female DSI is uncorrelated with dominance rank in this data set (Pearson's $R=0.11$, $p=0.468$ ), allowing us to assess the overlap between DSI and rank associations with gene expression independently of a correlation between the predictor variables themselves. While male social bonds to females also predict male survival [45], our DSI data set for males ( $n=30$ unique individuals) was too small to support a parallel analysis.

Controlling for dominance rank and other biological and technical sources of variance, we identified 529 DSI-associated genes (5.1\% of genes tested) in female Amboseli baboons $\left(\beta_{\mathrm{DSI}} \neq 0\right.$ in a linear mixed effects model; $10 \%$ FDR; Table S2). The vast majority of cases (522 genes, 98.6\%) were specifically identified in the LPS-stimulated condition, although gene-level DSI effect sizes are correlated between conditions (Pearson's $R=0.524, p<10^{-50}$ ). Surprisingly, genes that were more highly expressed in females with strong social bonds (high DSI) also tended to be more highly expressed in low-ranking females, and vice versa, resulting in a positive correlation between the parameter estimates for rank and DSI (at baseline: Pearson's $\mathrm{R}=0.516$; in LPS-stimulated samples: $\mathrm{R}=0.351$; Fig S5; note that the positive correlation arises 
because low ordinal rank values reflect high rank: i.e., the top-ranked female has an ordinal rank of 1 and lower ranked females have ranks $>1$ ).

This result was counterintuitive to us because strong social bonds predict longer lifespan in Amboseli baboon females [45], but the inflammation-related pathways associated with low female rank in this population are commonly thought to be costly to health $[82,83]$. We therefore investigated the pathways that account for the correlation in rank and DSI effect sizes at baseline. We found that this correlation is not, in fact, driven by immune process and inflammation-related genes: social environmental effects on these genes are specific to rank, and absent for social bond strength (Fig 2A). Specifically, genes involved in the inflammatory response are highly enriched for upregulated expression in low-ranking females at baseline $\left(p_{a d j}<0.005\right)$ and the majority of genes in this set exhibit a positive effect size (i.e., increased expression with lower rank: binomial test $p=2.35 \times 10^{-12}$ ). In contrast, there is no enrichment of inflammation-related genes for DSI ( $\left.p_{\text {adj }}>.05\right)$, nor any bias in the sign of the DSI effect $(p=$ 0.868). Consistent with these observations, accessible binding sites for TFs active in the immune response (e.g., STAT5, Smad3, STAT3) are not enriched in or near DSI-upregulated genes (all p > 0.5; Table S7). Instead, the overall correlation in rank and DSI effect sizes is driven by genes involved in cellular metabolism and cell cycle control, particularly targets of the transcription factor myc and genes that function in fatty acid metabolism and oxidative phosphorylation (both $\mathrm{p}_{\mathrm{adj}}<0.005$; Fig $2 \mathrm{~A}-\mathrm{B}$ ).

Notably, while genes involved in immune defense are not associated with DSI at baseline, a number of immune-related gene sets are significantly enriched for large DSI effects in the LPS-stimulated condition. After LPS stimulation, high social bond strength predicts higher expression of genes involved in the inflammatory response $\left(p_{a d j}=2.0 \times 10^{-3}\right)$. Because these genes are not detectably associated with DSI in baseline samples, this observation suggests a potential interaction between social bond strength and the cellular environment after bacterial exposure. In support of this possibility, DSI predicts the magnitude of the response to LPS (i.e., the foldchange difference between LPS and baseline samples, within females) for 200 genes (10\% FDR; Fig 2C; Table S8). Females with strong social bonds nearly always exhibit a more dynamic response to LPS than those with weaker social bonds (binomial test for LPSupregulated genes: $p=1.55 \times 10^{-10}$; binomial test for LPS-downregulated genes: $p=3.12 \times 10^{-}$ LPS conditions, rank does not predict the magnitude of the response to LPS (1 rank-associated gene; $10 \%$ FDR; Table S8). While many of the associations between DSI and the LPS response occur in immune pathways (Fig. 2C), females with stronger social bonds also exhibit markedly stronger responses to LPS in key cellular metabolism genes, including a key enzyme that catalyzes transitions through the Krebs cycle $(F H: q=0.024$; Fig 2D). 
A

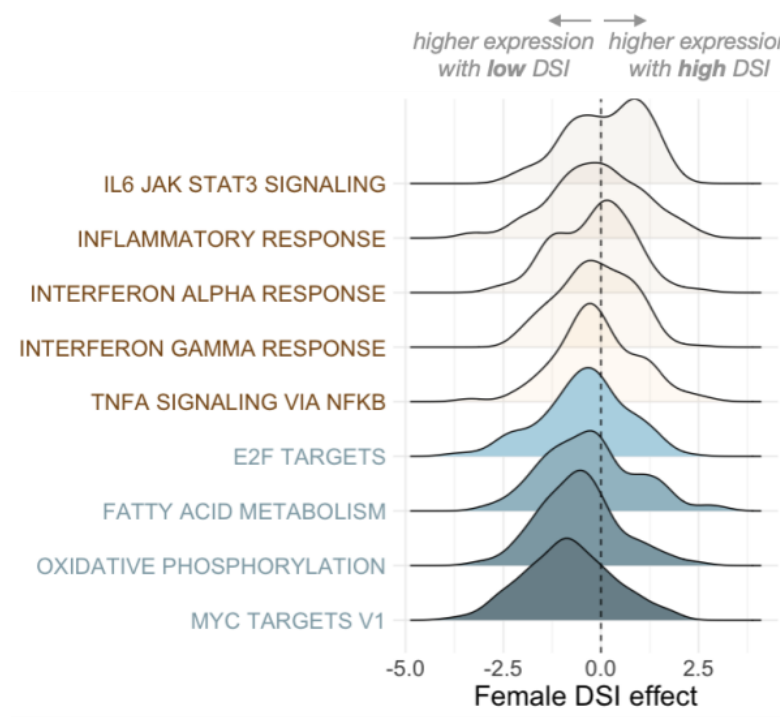

B Inflammatory response

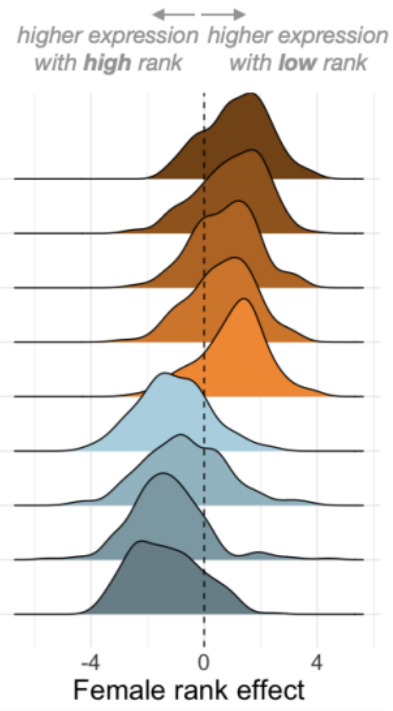

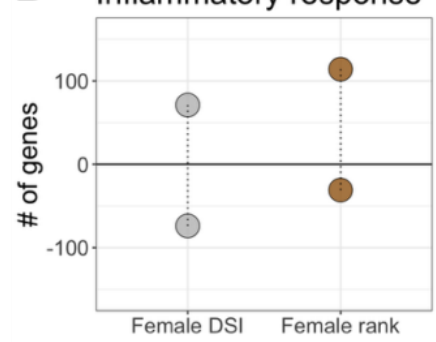

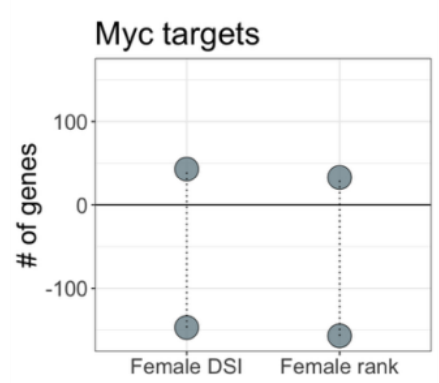

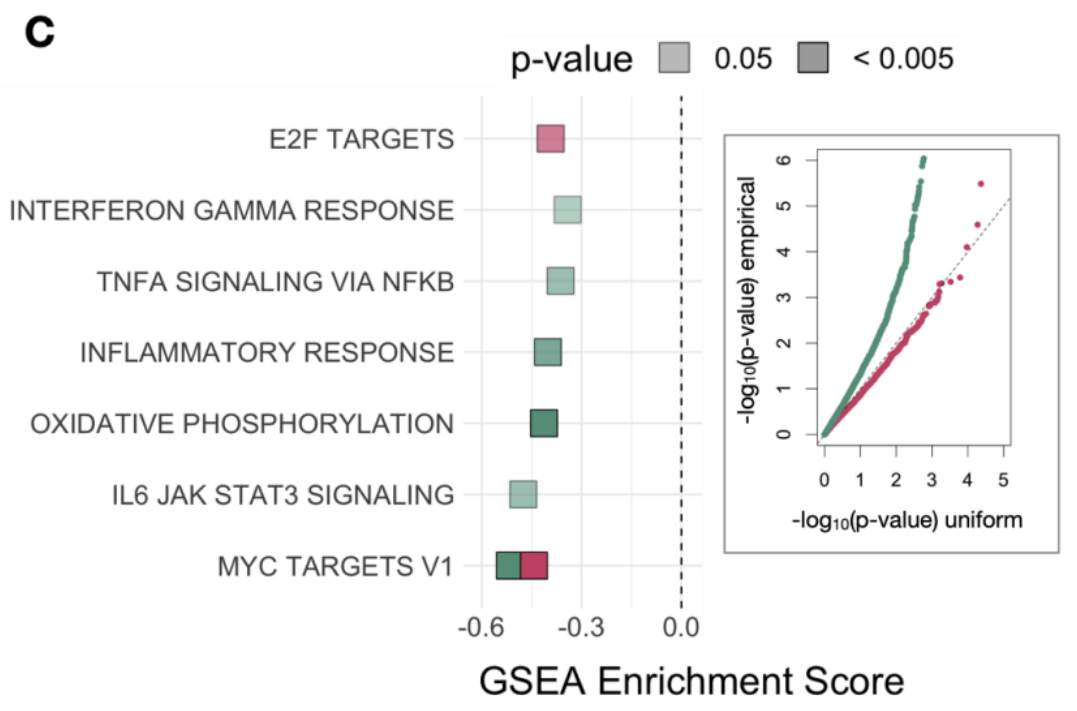

D 1.5
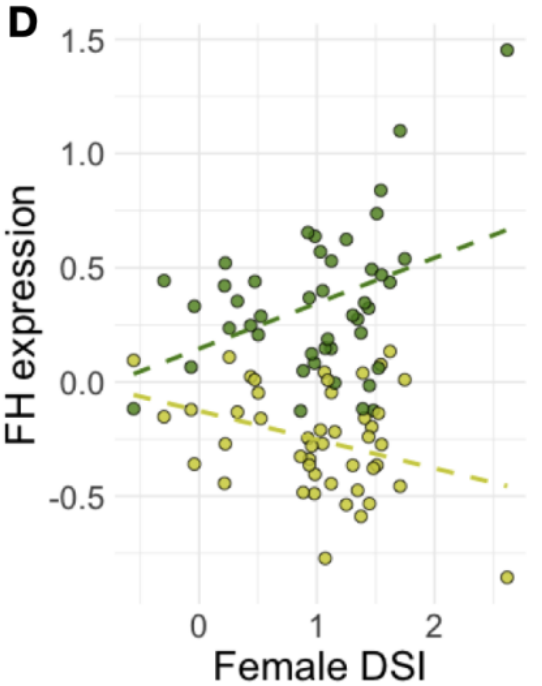

Stronger response with Low rank \& $\longleftarrow \square$ F DSI $\square$ F rank

Baseline $\square$ LPS High DSI

Figure 2. Social status and social bond strength predict distinct patterns of gene expression. (A) Distribution of DSI effects (left) and rank effects (right) on gene expression at baseline for genes within the MolSigDB Hallmark gene sets labeled at left. Genes within immune-related pathways (red/orange) are polarized towards higher expression in low-ranking females (positive effect sizes, because low rank is represented by high ordinal rank values). In contrast, genes in the same pathways show no pattern for association with DSI (small effect sizes centered on zero). Cellular metabolism and cell cycle-related gene sets (blue) tended to be more highly expressed with high rank (negative effect sizes) and low DSI (negative effect sizes). Translucent density plots indicate no significant bias in the direction of effects (binomial test $p>0.05$ ). (B) Effect size bias for genes in the Hallmark inflammatory response and myc (v1) target gene sets, for DSI and rank respectively. (C) Gene set enrichment analysis results for female DSI (green) and rank (pink) effects on the foldchange response to LPS stimulation. Inset: $Q Q$-plot of the - $\log _{10}(p$-value) for DSI and rank effects on the LPS response, relative to a uniform null distribution. We observe strong evidence for associations between DSI and the LPS response, but not for rank. (D) Example of FH, a key enzyme in the Krebs cycle that responds more strongly to LPS in high DSI females than low DSI females. 


\section{Gene expression patterns and multidimensional social advantage}

To investigate the combined signatures of social status and social bond strength, we asked whether females that were relatively advantaged in both respects-and who therefore experienced advantages to both fertility and survival $[44,45,75,84]$ — appeared physiologically distinct from other females. To do so, we binned females into four categories, corresponding to high rank/high DSI, high rank/low DSI, low rank/high DSI, and low rank/low DSI (stratified based on median rank and median DSI values in our sample). This classification reveals that, at baseline, high rank/high DSI females exhibited the lowest median expression values of genes in the Hallmark inflammatory response and IL6 signaling via JAK/STAT3 gene sets $(p<0.05$ for Wilcoxon summed ranks test of high rank/high DSI females against all three other categories, for both gene sets; Fig 3). Thus, females with social capital in both dimensions-status and

A

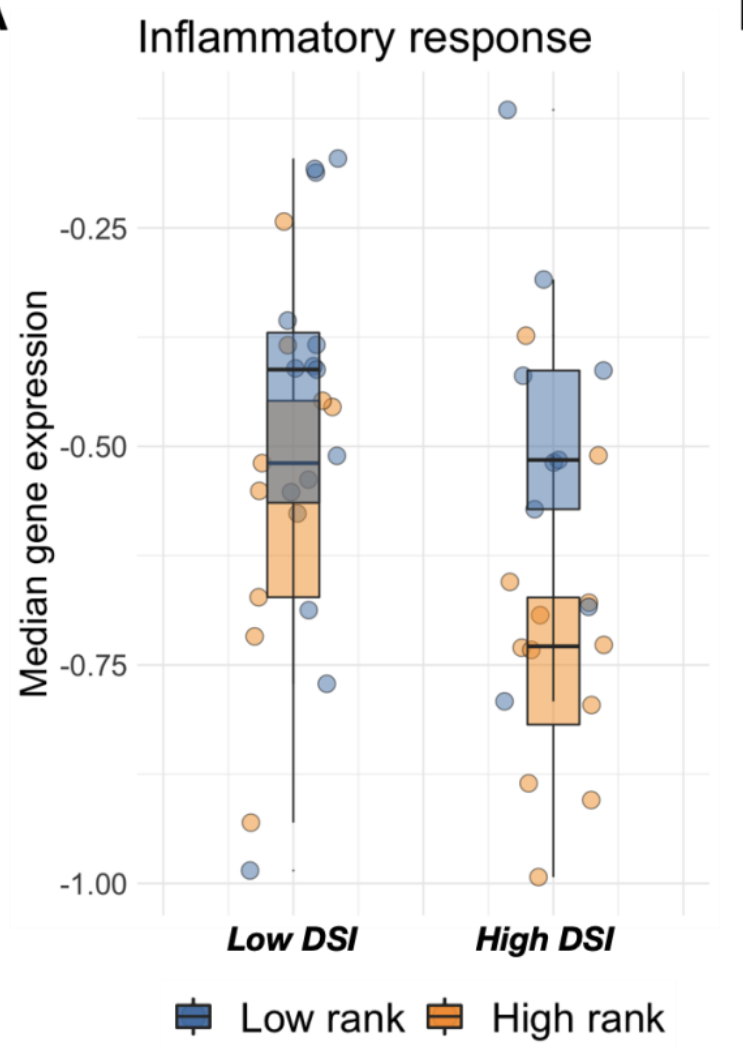

B

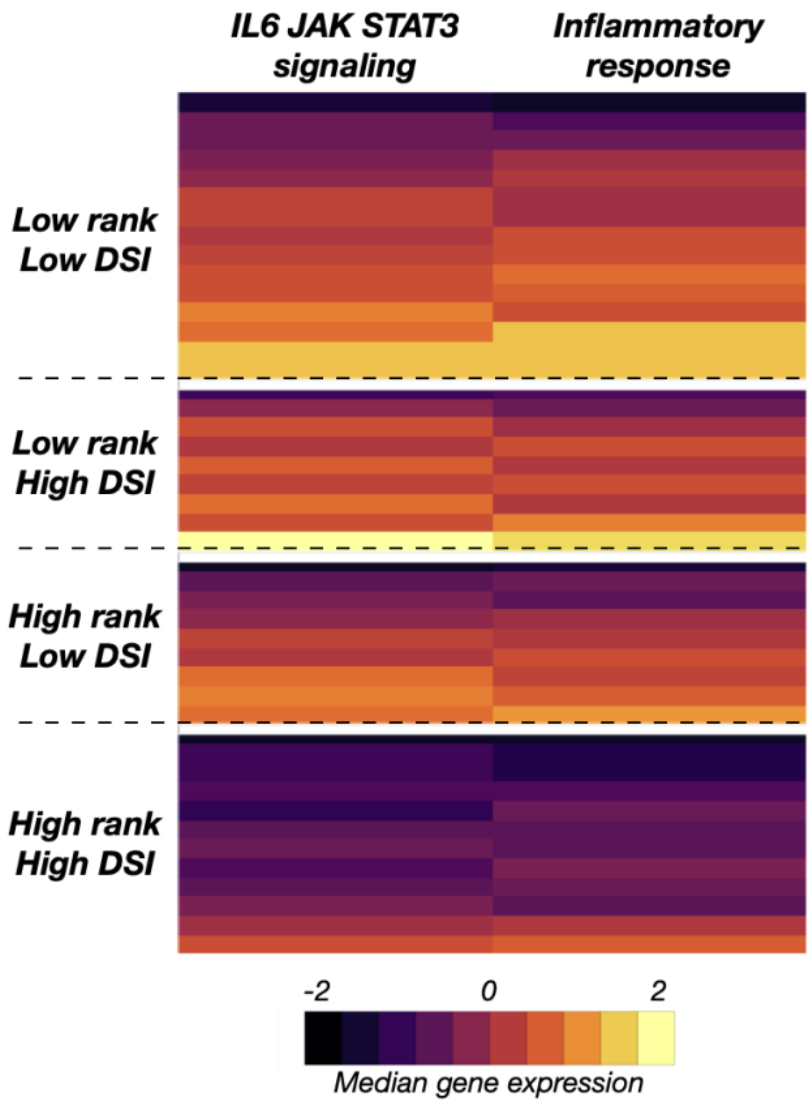

Figure 3. The gene expression signature of multidimensional social advantage. (A) Median gene expression for genes in the inflammatory response gene set illustrates that high ranking animals exhibit lower inflammation-related gene expression regardless of social bond strength (main effect of rank $=-0.15, p=0.019$ ). There is no main effect of DSI $(p=0.166)$, but the difference between high- and low-ranking females is greater when high-ranking females also have strong social bonds. (B) Median, rescaled gene expression per individual in the Hallmark IL6 signaling via JAK/STAT3 and the inflammatory response gene sets. Each row represents a different female, with rows stratified by median dominance rank and median DSI. 


\section{DISCUSSION}

Social interactions, both affiliative and competitive, determine much about the daily experience of group-living animals. Over the life course, these experiences compound to powerfully predict health, survival, and reproductive success. Our findings reinforce that the signature of the social environment is not only observable at the whole-organism level, but also in widespread differences in gene expression. They therefore contribute to a modest but expanding body of work linking gene expression variation to social experience in natural animal populations, in both the brain and the periphery $[15,70]$. Together, this work generalizes extensive research on social interactions and gene regulation in laboratory models $[67,85-87]$ to freely interacting animals in the wild. It also argues that correlations between gene expression, social status, and social integration in humans capture a broader pattern of molecular sensitivity to the social environment that predates the evolution of our own lineage $[66,88]$.

Our findings converge with much of the previous work in humans and captive primates to indicate that innate immune defense and cellular metabolism-related pathways are closely entwined with social experience [15,57,89-92]. However, the signature of social bond strength is much more apparent after immune stimulation than at baseline, and the signature of dominance rank is substantially stronger in male versus female baboons. Thus, the functional genomic signatures of different aspects of the social environment are themselves distinct. Our results are consistent with observations that the fertility and survival consequences of male rank, female rank, and female social bond strength also differ in this population $[29,44,45,75-$ 78]. They thus call the hypothesis of a strongly conserved signature of social disadvantage into question [66]. Tests for such a signature have particularly emphasized social disadvantagelinked increases in the expression of inflammation and interferon signaling-related genes. This prediction is supported for low rank in females but not for low social bond strength -and strikingly, is directionally reversed in male baboons.

Consequently, only female social status-related differences in gene expression recapitulate the pattern reported in studies of socioeconomic status, loneliness, and social integration in humans and experimental studies of dominance rank in captive female rhesus macaques $[57,89,91,93-97]$. Our results suggest that low social status in female baboons may therefore be a better model for social disadvantage in humans than low social status in male baboons-perhaps because social status in male baboons is driven almost entirely by fighting ability, which is not the primary determinant of social status in modern human societies. Indeed, social environment-associated gene expression signatures in humans are often interpreted through the lens of chronic psychosocial stress $[88,96,98]$. While the importance of chronic stress in natural animal populations remains an open question [11], low ranking females in both this study population, wild blue monkeys, and captive rhesus macaques do exhibit higher glucocorticoid levels and/or a blunted diurnal rhythm $[12,13,32,99]$. Psychosocial stress may therefore be the common explanatory factor underlying conserved signatures of social adversity, when they are observed. In contrast, high rank in baboon males imposes energetic stress due to competition with other males and the demands of mate-guarding [29,100], although males may experience forms of psychosocial stress as well. And while the stability of social hierarchies and experimental work in captive primates suggests that rank precedes the gene expression patterns we observe in females, males that achieve high rank may already be physiologically distinct [15]. 
This explanation does not, however, account for why social bond strength does not follow the same pattern as female dominance rank. Weak social bond strength in Amboseli baboon females is also correlated with elevated glucocorticoid levels, although this effect is modest in comparison to other predictors (e.g., early life adversity [101]). If glucocorticoids are a major determinant of social environment-associated variation in immune pathway gene expression, these observations may account for why (unlike rank) we did not observe a strong signature of social bond strength in immune genes at baseline. Instead, social bond strength is most consistently linked to oxidative phosphorylation and myc signaling (a key regulator of cell growth, metabolism, and apoptosis). Intriguingly, myc activity has also been implicated in social regulation of brain gene expression in mice and as a mediator of social isolation-induced cancer susceptibility in mice and rats [64,102]. These observations suggest that social bond strength may be involved in altered energy metabolism and energetics in the baboons, as suggested in other studies of chronic and/or psychosocial stress [103].

Together, our findings emphasize substantial complexity in how the social environment is reflected at the molecular level. If we had focused only on an a priori subset of genes in the genome, we could have concluded that social interactions do not predict gene expression levels at all; that social status, but not social affiliation, predicts gene expression; or that social status and social affiliation generate highly similar gene expression signatures. Similarly, if we had focused only on one sex, we would have missed the shared sensitivity, but reversed directionality, of status-related pathways in males versus females. Finally, if we had only measured gene expression levels at baseline, we would have inferred that social bond strength has little relevance to immune gene regulation, when in fact it is a much better predictor of variation in the response to immune stimulation than dominance rank. While this complexity presents a challenge-additional dimensions we did not explore, including developmental, tissue, and cell type differences, are also likely to be important-it also illustrates the potential for high-dimensional genomic data to capture heterogeneity in the signature of social relationships that is impossible to infer from single measures. Indeed, our results suggest that, even in the blood, social regulation of gene expression must be the consequence of multiple upstream signaling pathways. Future studies thus have the opportunity both to test existing hypotheses about the role of glucocorticoids in social environment-associated gene regulation, and to identify alternative pathways that may also play an important role.

\section{Methods:}

Study subjects and samples

Study subjects were 97 adult baboons (52 males; 45 females) sampled from an intensively monitored population of hybrid yellow baboons (Papio cynocephalus) and anubis baboons (Papio anubis) in the Amboseli ecosystem of southern Kenya [104,105]. Genome-wide gene expression measures were generated from blood samples collected during opportunistic dartings from 2013 - 2018. Data from samples collected in $2013-2016$ were previously reported in [15], while the remaining 76 samples are newly reported here (Table S1). For all sampling efforts, subjects were anesthetized using Telazol-loaded darts and safely removed from their social groups for sample collection (as in [15,106,107]). Darted individuals were allowed to recover from anesthesia and released to their social group the same day. 
For each study subject, we drew $1 \mathrm{~mL}$ of blood directly into a sterile TruCulture tube (Myriad RBM) containing cell media only (the baseline sample), and another $1 \mathrm{~mL}$ of blood into a second TruCulture tube containing cell media plus $0.1 \mathrm{ug} / \mathrm{mL}$ lipopolysaccharide (LPS; Fig 1A). Samples were incubated for 10 hours at $37 \mathrm{C}$. Following incubation, white blood cells were extracted and stored in RNALater at -20 C until further processing. To control for cell type composition, we also measured peripheral blood mononuclear cell type proportions for five major cell types, for each individual. To do so, we purified peripheral blood mononuclear cells (PBMCs) from blood drawn into Cell Preparation Tubes (CPT tubes; BD Biosciences) and stained the PBMCs using fluorophore-conjugated antibodies to the cell surface markers CD3, CD14, CD16, CD8, and CD20, which together differentiate classical monocytes (CD3 $/ \mathrm{CD}^{-} 4^{+}$ CD16), natural killer cells (CD3 $/$ CD14 $\left./ \mathrm{CD}^{-} 6^{+}\right)$, B-cells $\left(\mathrm{CD}^{-} / \mathrm{CD}^{2} 0^{+}\right)$, helper T-cells $\left(\mathrm{CD}^{+} / \mathrm{CD}^{+} / \mathrm{CD} 8\right)$, and cytotoxic T-cells (CD3 $\left.{ }^{+} / \mathrm{CD} 4 / \mathrm{CD}^{+}\right)$[15]. PBMC composition was then profiled on a BD FacsCalibur flow cytometer and analyzed in FlowJo 10.7.1 (Table S1 with additional cell type discrimination based on cell size and granularity).

To measure chromatin accessibility, $50 \mathrm{~mL}$ of blood was drawn from three male anubis baboons housed at Texas Biomedical Research Institute's Southwest National Primate Research Center into CPT tubes (BD Biosciences), spun for 30 minutes at 1800 rcf, and shipped to Duke University for PBMC isolation. 50,000 PBMCs from each individual were incubated for 10 hours at $37 \mathrm{C}$ and $5 \% \mathrm{CO}_{2}$ in either the presence or absence of LPS $(0.1$ $\mathrm{ug} / \mathrm{mL}$, Invivogen ultrapure LPS from E. coli strain 055:B5). We then generated ATAC-seq libraries from 50,000 cells per sample ( $n=6$ baseline and LPS-stimulated samples total from the 3 baboons; see SI Methods; [108]).

\section{Dominance rank and social bond strength}

Sex-specific dominance ranks are assigned each month for each social group in the study population based on the outcomes of dyadic agonistic interactions observed on a neardaily basis $[104,109]$. Dominance rank assignments produce a hierarchy structure that minimizes the number of cases in which higher ranking individuals lose interactions to lower ranking ones [110]. To investigate rank-gene expression associations, we extracted ordinal dominance rank values concurrent with blood sample collection, which represent rank as integer values where rank 1 denotes the top-ranking individual, rank 2 denotes the second highestranking individual, and so on. We note that previous analyses in this and other social mammals show that alternative rank metrics sometimes confer improved predictive power [110,111]. In the Amboseli baboon population, this is especially observable in females, where proportional rank (i.e., ordinal rank scaled by group size) is more closely associated with fecal glucocorticoid levels and injury risk than ordinal rank [110]. In this data set, substituting ordinal rank for proportional rank produces highly concordant effect size estimates ( $R^{2}$ for baseline male, LPS male, baseline female, and LPS female rank effects $=0.75,0.79,0.88,0.85$, respectively), so we reported the results for ordinal rank for both sexes.

To measure social bond strength, we used the dyadic sociality index (DSI, as in $[45,80,101])$. The DSI calculates the mean grooming-based bond strength between a focal female and her top three grooming partners in the year prior to sample collection, controlling for observer effort and dyad co-residency times (see details in the Supplementary Methods). High 
DSI values thus correspond to strong social bonds, and low DSI values correspond to weak social bonds.

\section{Genomic data generation}

For gene expression measurements, RNA was extracted from each sample ( $n=195$ from $\mathrm{n}=97$ unique baboons) using the Qiagen RNeasy kit, following manufacturer's instructions (mean $\mathrm{RIN}=9.19$ in a random subset of $n=21$ samples). We constructed indexed RNA-seq libraries using the NEBNext Ultra I or II library prep kits, followed by paired-end sequencing on an Illumina HiSeq 2500 (for samples collected from 2013 - 2016) or single-end on a HiSeq 4000 (for samples collected after 2016) to a mean depth of 17.4 million reads ( \pm 7.7 million SD; Table S1). Trimmed reads were mapped to the Panubis 1.0 genome (GCA_008728515.1) using the STAR 2-pass aligner [112,113]. Finally, we generated gene-level counts using HTSeq and the Panubis1.0 annotation (GCF_008728515.1) [114]. We retained genes with median RPKM > 2 in the baseline samples, LPS samples, or both for downstream analysis ( $n=10,281$ genes).

For chromatin accessibility estimates, ATAC-seq libraries were sequenced on a HiSeq 2500 to a mean depth of 40.0 million paired-end reads ( \pm 13.7 million SD; Table S5). Trimmed reads were mapped to the Panubis 1.0 genome using BWA [115]. We then combined mapped reads across samples in the same condition (baseline or LPS) and called chromatin accessibility peaks for each condition separately using MACS2 (see Supplementary Methods; [116]).

\section{Gene expression analysis}

To identify social environment associations with gene expression, we first normalized the gene expression data set using voom [117] and regressed out year of sampling (the primary source of batch effects in our data set), sequencing depth, and the first three principal components summarizing cell type composition using limma [118]. For each gene, we then modeled the resulting residuals as the response variable in a sex-specific linear mixed model including the fixed effects of treatment (LPS or baseline), dominance rank, DSI (for females only), age, and a random effect that controls for kinship and population structure [119]. We nested age, rank, and DSI within treatment condition to evaluate condition-specific versus shared effects. To estimate genetic covariance between individuals, which is required for the random effect estimates, we genotyped samples from the RNA-seq data using the Genome Analysis Toolkit (see Supplementary Methods; [120]). To control for multiple hypothesis testing, we calculated false discovery rates using the $\mathrm{R}$ package qvalue after verifying the empirical null was uniformly distributed [121].

To investigate how social interactions influence the response to LPS treatment, we calculated an equivalent to the fold-change in residual gene expression between paired LPS and baseline samples in the 44 females with both samples available. We then modeled this response using a mixed effects model, with fixed effects of age, dominance rank, and DSI, and a random effect to control for genetic relatedness/population structure. To test for enrichment of specific gene sets among rank- or DSI-associated genes, we used Gene Set Enrichment Analysis (GSEA; [122]), across the 50 Hallmark gene sets in the Molecular Signatures Database (MolSigDB; [81]). We assessed the significance of pathway enrichment scores via 
comparison to 10,000 random permutations of gene labels across pathways, and controlled for multiple hypothesis testing using a Bonferroni correction.

All statistical analyses in this section and below were performed in $R$ ( $R$ version 3.6.1; [123]).

\section{Elastic net rank predictions}

To generate predictive models for rank, we used the elastic net approach implemented in the R package glmnet [124]. For within-sex predictions, samples from the same treatment condition (baseline or LPS) were iteratively removed from the training set. An elastic net model was then trained using $\mathrm{N}$-fold internal cross-validation on the remaining samples, and rank was predicted from the normalized gene expression data for the left-out test sample (see Supplementary Methods). To predict across sex, we trained a single model on all samples from a single treatment-sex combination, and used the model to predict rank for all samples from animals of the other sex, collected in the same treatment condition.

\section{Transcription factor binding motif enrichment}

To investigate transcription factor binding motif (TFBM) enrichment, we focused on the 5 $\mathrm{kb}$ sequence upstream of rank or DSI-associated genes. We intersected these regions with areas of open chromatin called from the ATAC-seq samples, merged within treatment (e.g. the combined baseline or combined LPS samples). We then performed TFBM enrichment analysis in these regions for rank- or DSI-associated genes relative to the background set of all expressed genes using Homer (see Supplementary Methods) [125].

\section{Data accessibility}

The sequencing data analyzed here have been deposited in the NCBI Short Read Archive under BioProject (PRJNA480672) for previously published data, PRJNA731520 for newly generated RNA-seq data, and PRJNA731674 for baboon PBMC ATAC-seq data. Data analysis and figure code is deposited at https://github.com/janderson94/Anderson et al distinct social signatures.

\section{Funding} 539 Research (Child \& Brain Development Program) and support for high-performance computing

We gratefully acknowledge the support provided by the National Science Foundation and the National Institutes of Health for the majority of the data represented here, currently through NSF IOS 1456832, NIH R01AG053308, R01AG053330, R01HD088558, and P01AG031719. J.A.A. was supported by a Triangle Center for Evolutionary Medicine Graduate Student Award and by National Science Foundation Graduate Research Fellowship Program \#2018264636. AJL was supported by a postdoctoral fellowship from the Helen Hay Whitney Foundation. LO is funded by the African Research Network for Neglected Tropical Diseases (ARNTD) SGPIII/0210/351. We also acknowledge support from Duke University (including an Undergraduate Research Support grant to $\mathrm{YZ}$ ) and the Canadian Institute of Advanced resources from the North Carolina Biotechnology Center (Grant Number 2016-IDG-1013).

\section{Acknowledgements}


We thank members of the Amboseli Baboon Research Project for collecting the data presented here, especially J. Altmann for her foundational role in establishing the study population and these data sets. We also thank J. Gordon, N. Learn, and K. Pinc for managing the database, R.S. Mututua, S. Sayialel, I.L. Siodi, and J.K. Warutere for data collection in the field, and T. Wango and V. Oudu for their assistance in Nairobi. Our research was approved by the Kenya Wildlife Service (KWS), the National Commission for Science, Technology, and Innovation (NACOSTI), and the National Environmental Management Authority (NEMA) in Kenya. We also thank the University of Nairobi, the Institute of Primate Research (IPR), the National Museums of Kenya, the members of the Amboseli-Longido pastoralist communities, the Enduimet Wildlife Management Area, Ker \& Downey Safaris, Air Kenya, and Safarilink for their cooperation and assistance in the field. This research was approved by the IACUC at Duke University and University of Notre Dame, and adhered to all the laws and guidelines of Kenya. For a complete set of acknowledgments of funding sources, logistical assistance, and data collection and management, please visit http://amboselibaboons.nd.edu/acknowledgements/.

\section{References}

561

1. Rubenstein DI. On predation, competition, and the advantages of group living. In: Social behavior. Springer; 1978. p. 205-31.

2. Wilson EO. Sociobiology: The new synthesis. Harvard University Press; 2000.

3. Krause J, Ruxton GD, Ruxton G, Ruxton IG. Living in groups. Oxford University Press; 2002.

4. Van Schaik CP. Why are diurnal primates living in groups? Behaviour. 1983;87(12):120-44.

5. Schjelderup-Ebbe T. Contributions to the social psychology of the domestic chicken. Repr from Zeitschrift fuer Psychol. 1922;88:225-52.

6. Sapolsky RM. Social status and health in humans and other animals. Annu Rev Anthr. 2004;33:393-418.

7. Holekamp KE, Strauss ED. Aggression and dominance: an interdisciplinary overview. Curr Opin Behav Sci. 2016;12:44-51.

8. Abbott DH, Keverne EB, Bercovitch FB, Shively CA, Mendoza SP, Saltzman W, et al. Are subordinates always stressed? A comparative analysis of rank differences in cortisol levels among primates. Horm Behav. 2003;43(1):67-82.

9. Cavigelli SA, Caruso MJ. Sex, social status and physiological stress in primates: the importance of social and glucocorticoid dynamics. Philos Trans R Soc B Biol Sci. 2015;370(1669):20140103.

10. Creel S. Dominance, aggression, and glucocorticoid levels in social carnivores. J Mammal. 2005;86(2):255-64.

11. Beehner JC, Bergman TJ. The next step for stress research in primates: To identify relationships between glucocorticoid secretion and fitness. Horm Behav. 2017;91:68-83.

12. Kohn JN, Snyder-Mackler N, Barreiro LB, Johnson ZP, Tung J, Wilson ME. Dominance rank causally affects personality and glucocorticoid regulation in female rhesus macaques. Psychoneuroendocrinology. 2016;74:179-88.

13. Levy EJ, Gesquiere LR, McLean E, Franz M, Warutere JK, Sayialel SN, et al. Higher dominance rank is associated with lower glucocorticoids in wild female baboons: a rank metric comparison. Horm Behav. 2020;125:104826.

14. Gesquiere LR, Learn NH, Simao MCM, Onyango PO, Alberts SC, Altmann J. Life at the top: rank and stress in wild male baboons. Science (80- ). 2011;333(6040):357-60. 
591

592

593

594

595

596

597

598

599

600

601

602

603

604

605

606

607

608

609

610

611

612

613

614

615

616

617

618

619

620

621

622

623

624

625

626

627

628

629

630

631

632

633

634

635

636

637

638

639

640

641

associated gene expression is widespread, sex-specific, and a precursor to high social status in wild male baboons. Proc Natl Acad Sci. 2018;115(52):E12163-71.

16. Bergman TJ, Beehner JC, Cheney DL, Seyfarth RM, Whitten PL. Correlates of stress in free-ranging male chacma baboons, Papio hamadryas ursinus. Anim Behav. 2005;70(3):703-13.

17. Rubenstein DR, Shen S-F. Reproductive conflict and the costs of social status in cooperatively breeding vertebrates. Am Nat. 2009;173(5):650-61.

18. Carlson AA, Young AJ, Russell AF, Bennett NC, McNeilly AS, Clutton-Brock T. Hormonal correlates of dominance in meerkats (Suricata suricatta). Horm Behav. 2004;46(2):14150.

19. Kruuk LEB, Slate J, Pemberton JM, Brotherstone S, Guinness F, Clutton-Brock T. Antler size in red deer: heritability and selection but no evolution. Evolution (N Y). 2002;56(8):1683-95.

20. Samuels A, Gifford T. A quantitative assessment of dominance relations among bottlenose dolphins. Mar Mammal Sci. 1997;13(1):70-99.

21. Hodge SJ, Manica A, Flower TP, Clutton-Brock TH. Determinants of reproductive success in dominant female meerkats. J Anim Ecol. 2008;77(1):92-102.

22. Strauss ED, Holekamp KE. Social alliances improve rank and fitness in convention-based societies. Proc Natl Acad Sci. 2019;116(18):8919-24.

23. Lea AJ, Learn NH, Theus MJ, Altmann J, Alberts SC. Complex sources of variance in female dominance rank in a nepotistic society. Anim Behav. 2014;94:87-99.

24. Hausfater G, Altmann J, Altmann S. Long-term consistency of dominance relations among female baboons (Papio cynocephalus). Science (80- ). 1982;217(4561):752-5.

25. Holekamp KE, Smale L. Dominance acquisition during mammalian social development: the "inheritance" of maternal rank. Am Zool. 1991;31(2):306-17.

26. Holekamp KE, Smith JE, Strelioff CC, Van Horn RC, Watts HE. Society, demography and genetic structure in the spotted hyena. Mol Ecol. 2012;21(3):613-32.

27. Wroblewski EE, Murray CM, Keele BF, Schumacher-Stankey JC, Hahn BH, Pusey AE. Male dominance rank and reproductive success in chimpanzees, Pan troglodytes schweinfurthii. Anim Behav. 2009;77(4):873-85.

28. Altmann J, Alberts SC. Variability in reproductive success viewed from a life-history perspective in baboons. Am J Hum Biol. 2003;15(3):401-9.

29. Alberts SC, Watts HE, Altmann J. Queuing and queue-jumping: long-term patterns of reproductive skew in male savannah baboons, Papio cynocephalus. Anim Behav. 2003;65(4):821-40.

30. Cowlishaw G, Dunbar RIM. Dominance rank and mating success in male primates. Anim Behav. 1991;41(6):1045-56.

31. Clutton-Brock T. Mammal societies. John Wiley \& Sons; 2016.

32. Foerster S, Cords M, Monfort SL. Social behavior, foraging strategies, and fecal glucocorticoids in female blue monkeys (Cercopithecus mitis): potential fitness benefits of high rank in a forest guenon. Am J Primatol. 2011;73(9):870-82.

33. Solomon NG, French JA. Cooperative breeding in mammals. Cambridge University Press; 1997.

34. Cavigelli SA, Dubovick T, Levash W, Jolly A, Pitts A. Female dominance status and fecal corticoids in a cooperative breeder with low reproductive skew: ring-tailed lemurs (Lemur catta). Horm Behav. 2003;43(1):166-79.

35. Muller MN, Enigk DK, Fox SA, Lucore J, Machanda ZP, Wrangham RW, et al. Aggression, glucocorticoids, and the chronic costs of status competition for wild male chimpanzees. Horm Behav. 2021;130:104965.

36. Dunbar RIM. Functional significance of social grooming in primates. Folia Primatol. $1991 ; 57(3): 121-31$. 
642

643

644

645

646

647

648

649

650

651

652

653

654

655

656

657

658

659

660

661

662

663

664

665

666

667

668

669

670

671

672

673

674

675

676

677

678

679

680

681

682

683

684

685

686

687

688

689

690

691

692

37. Mann J. Behavioral sampling methods for cetaceans: a review and critique. Mar mammal Sci. 1999;15(1):102-22.

38. Stanton MA, Mann J. Early social networks predict survival in wild bottlenose dolphins. PLoS One. 2012;7(10):e47508.

39. Sundaresan SR, Fischhoff IR, Dushoff J, Rubenstein DI. Network metrics reveal differences in social organization between two fission-fusion species, Grevy's zebra and onager. Oecologia. 2007;151(1):140-9.

40. Schino G. Grooming and agonistic support: a meta-analysis of primate reciprocal altruism. Behav Ecol. 2007;18(1):115-20.

41. Seyfarth RM, Cheney DL. Grooming, alliances and reciprocal altruism in vervet monkeys. Nature. 1984;308(5959):541-3.

42. Snyder-Mackler N, Kohn JN, Barreiro LB, Johnson ZP, Wilson ME, Tung J. Social status drives social relationships in groups of unrelated female rhesus macaques. Anim Behav. 2016;111:307-17.

43. Kutsukake N, Clutton-Brock TH. Grooming and the value of social relationships in cooperatively breeding meerkats. Anim Behav. 2010;79(2):271-9.

44. Archie EA, Tung J, Clark M, Altmann J, Alberts SC. Social affiliation matters: both samesex and opposite-sex relationships predict survival in wild female baboons. In: Proc $R$ Soc B. The Royal Society; 2014. p. 20141261.

45. Campos FA, Villavicencio F, Archie EA, Colchero F, Alberts SC. Social bonds, social status and survival in wild baboons: a tale of two sexes. Philos Trans R Soc B. 2020;375(1811):20190621.

46. Barocas A, llany A, Koren L, Kam M, Geffen E. Variance in centrality within rock hyrax social networks predicts adult longevity. PLoS One. 2011;6(7):e22375.

47. Nuñez CM V, Adelman JS, Rubenstein DI. Sociality increases juvenile survival after a catastrophic event in the feral horse (Equus caballus). Behav Ecol. 2015;26(1):138-47.

48. Ellis S, Franks DW, Nattrass S, Cant MA, Weiss MN, Giles D, et al. Mortality risk and social network position in resident killer whales: sex differences and the importance of resource abundance. Proc R Soc B Biol Sci. 2017;284(1865):20171313.

49. Holt-Lunstad J, Smith TB, Layton JB. Social relationships and mortality risk: a metaanalytic review. PLoS Med. 2010;7(7):e1000316.

50. Vander Wal E, Festa-Bianchet M, Réale D, Coltman DW, Pelletier F. Sex-based differences in the adaptive value of social behavior contrasted against morphology and environment. Ecology. 2015;96(3):631-41.

51. Silk JB, Beehner JC, Bergman TJ, Crockford C, Engh AL, Moscovice LR, et al. Strong and consistent social bonds enhance the longevity of female baboons. Curr Biol. 2010;20(15):1359-61.

52. Snyder-Mackler N, Burger JR, Gaydosh L, Belsky DW, Noppert GA, Campos FA, et al. Social determinants of health and survival in humans and other animals. Science. 2020;368(6493).

53. Wittig RM, Crockford C, Weltring A, Langergraber KE, Deschner T, Zuberbühler K. Social support reduces stress hormone levels in wild chimpanzees across stressful events and everyday affiliations. Nat Commun. 2016;7(1):1-8.

54. Crockford C, Wittig RM, Whitten PL, Seyfarth RM, Cheney DL. Social stressors and coping mechanisms in wild female baboons (Papio hamadryas ursinus). Horm Behav. 2008;53(1):254-65.

55. Wittig RM, Crockford C, Lehmann J, Whitten PL, Seyfarth RM, Cheney DL. Focused grooming networks and stress alleviation in wild female baboons. Horm Behav. 2008;54(1):170-7.

56. Young C, Majolo B, Heistermann M, Schülke O, Ostner J. Responses to social and environmental stress are attenuated by strong male bonds in wild macaques. Proc Natl 
693

694

695

696

697

698

699

700

701

702

703

704

705

706

707

708

709

710

711

712

713

714

715

716

717

718

719

720

721

722

723

724

725

726

727

728

729

730

731

732

733

734

735

736

737

738

739

740

741

742

743
Acad Sci. 2014;111(51):18195-200.

57. Cole SW, Hawkley LC, Arevalo JM, Sung CY, Rose RM, Cacioppo JT. Social regulation of gene expression in human leukocytes. Genome Biol. 2007;8(9):1-13.

58. Yang YC, McClintock MK, Kozloski M, Li T. Social isolation and adult mortality: the role of chronic inflammation and sex differences. J Health Soc Behav. 2013;54(2):183-203.

59. Smith KJ, Gavey S, RIddell NE, Kontari P, Victor C. The association between loneliness, social isolation and inflammation: A systematic review and meta-analysis. Neurosci Biobehav Rev. 2020;112:519-41.

60. Adam EK, Hawkley LC, Kudielka BM, Cacioppo JT. Day-to-day dynamics of experiencecortisol associations in a population-based sample of older adults. Proc Natl Acad Sci. 2006;103(45):17058-63.

61. Steptoe A, Owen N, Kunz-Ebrecht SR, Brydon L. Loneliness and neuroendocrine, cardiovascular, and inflammatory stress responses in middle-aged men and women. Psychoneuroendocrinology. 2004;29(5):593-611.

62. Valtorta NK, Kanaan M, Gilbody S, Ronzi S, Hanratty B. Loneliness and social isolation as risk factors for coronary heart disease and stroke: systematic review and metaanalysis of longitudinal observational studies. Heart. 2016;102(13):1009-16.

63. Reynolds P, Kaplan GA. Social connections and risk for cancer: prospective evidence from the Alameda County Study. Behav Med. 1990;16(3):101-10.

64. Hermes GL, Delgado B, Tretiakova M, Cavigelli SA, Krausz T, Conzen SD, et al. Social isolation dysregulates endocrine and behavioral stress while increasing malignant burden of spontaneous mammary tumors. Proc Natl Acad Sci. 2009;106(52):22393-8.

65. Sloan EK, Priceman SJ, Cox BF, Yu S, Pimentel MA, Tangkanangnukul V, et al. The sympathetic nervous system induces a metastatic switch in primary breast cancer. Cancer Res. 2010;70(18):7042-52.

66. Cole SW. The conserved transcriptional response to adversity. Curr Opin Behav Sci. 2019;28:31-7.

67. Renn SCP, Aubin-Horth N, Hofmann HA. Fish and chips: functional genomics of social plasticity in an African cichlid fish. J Exp Biol. 2008;211(18):3041-56.

68. Schumer M, Krishnakant K, Renn SCP. Comparative gene expression profiles for highly similar aggressive phenotypes in male and female cichlid fishes (Julidochromis). J Exp Biol. 2011;214(19):3269-78.

69. Renn SCP, O'Rourke CF, Aubin-Horth N, Fraser EJ, Hofmann HA. Dissecting the transcriptional patterns of social dominance across teleosts. Integr Comp Biol. 2016;56(6):1250-65.

70. Bentz AB, George EM, Wolf SE, Rusch DB, Podicheti R, Buechlein A, et al. Experimental competition induces immediate and lasting effects on the neurogenome in free-living female birds. Proc Natl Acad Sci. 2021;118(13).

71. Greenwood AK, Wark AR, Fernald RD, Hofmann HA. Expression of arginine vasotocin in distinct preoptic regions is associated with dominant and subordinate behaviour in an African cichlid fish. Proc R Soc B Biol Sci. 2008;275(1649):2393-402.

72. Rittschof CC, Bukhari SA, Sloofman LG, Troy JM, Caetano-Anollés D, Cash-Ahmed A, et al. Neuromolecular responses to social challenge: Common mechanisms across mouse, stickleback fish, and honey bee. Proc Natl Acad Sci. 2014;111(50):17929-34.

73. Saul MC, Blatti C, Yang W, Bukhari SA, Shpigler HY, Troy JM, et al. Cross-species systems analysis of evolutionary toolkits of neurogenomic response to social challenge. Genes, Brain Behav. 2019;18(1):e12502.

74. Kanitz E, Puppe B, Tuchscherer M, Heberer M, Viergutz T, Tuchscherer A. A single exposure to social isolation in domestic piglets activates behavioural arousal, neuroendocrine stress hormones, and stress-related gene expression in the brain. Physiol Behav. 2009;98(1-2):176-85. 
75. Lea AJ, Altmann J, Alberts SC, Tung J. Developmental Constraints in a Wild Primate. Am Nat [Internet]. 2015 Jun 7;185(6):809-21. Available from: http://www.ncbi.nlm.nih.gov/pmc/articles/PMC4541805/

76. Altmann J, Alberts SC. Growth rates in a wild primate population: ecological influences and maternal effects. Behav Ecol Sociobiol. 2005;57(5):490-501.

77. Onyango PO, Gesquiere LR, Altmann J, Alberts SC. Puberty and dispersal in a wild primate population. Horm Behav. 2013;64(2):240-9.

78. Charpentier MJE, Tung J, Altmann J, Alberts SC. Age at maturity in wild baboons: genetic, environmental and demographic influences. Mol Ecol. 2008;17(8):2026-40.

79. Runcie DE, Wiedmann RT, Archie EA, Altmann J, Wray GA, Alberts SC, et al. Social environment influences the relationship between genotype and gene expression in wild baboons. Philos Trans R Soc B Biol Sci. 2013;368(1618):20120345.

80. Anderson JA, Johnston RA, Lea AJ, Campos FA, Voyles TN, Akinyi MY, et al. High social status males experience accelerated epigenetic aging in wild baboons. Perry $\mathrm{GH}$, editor. Elife [Internet]. 2021;10:e66128. Available from: https://doi.org/10.7554/eLife.66128

81. Liberzon A, Birger C, Thorvaldsdóttir H, Ghandi M, Mesirov JP, Tamayo P. The molecular signatures database hallmark gene set collection. Cell Syst. 2015;1(6):417-25.

82. Medzhitov R. Origin and physiological roles of inflammation. Nature. 2008;454(7203):428-35.

83. Franceschi C, Campisi J. Chronic inflammation (inflammaging) and its potential contribution to age-associated diseases. Journals Gerontol Ser A Biomed Sci Med Sci. 2014;69(Suppl_1):S4-9.

84. Gesquiere LR, Altmann J, Archie EA, Alberts SC. Interbirth intervals in wild baboons: Environmental predictors and hormonal correlates. Am J Phys Anthropol. 2018;166(1):107-26.

85. Hammels C, Pishva E, De Vry J, van den Hove DLA, Prickaerts J, van Winkel R, et al. Defeat stress in rodents: from behavior to molecules. Neurosci Biobehav Rev. 2015;59:111-40.

86. Alaux C, Sinha S, Hasadsri L, Hunt GJ, Guzmán-Novoa E, DeGrandi-Hoffman G, et al. Honey bee aggression supports a link between gene regulation and behavioral evolution. Proc Natl Acad Sci. 2009;106(36):15400-5.

87. Robinson GE, Grozinger CM, Whitfield CW. Sociogenomics: social life in molecular terms. Nat Rev Genet. 2005;6(4):257-70.

88. Cole SW. Human social genomics. PLoS Genet. 2014;10(8):e1004601.

89. Sanz J, Maurizio PL, Snyder-Mackler N, Simons ND, Voyles T, Kohn J, et al. Social history and exposure to pathogen signals modulate social status effects on gene regulation in rhesus macaques. Proc Natl Acad Sci [Internet]. 2019 Oct 14;201820846. Available from: http://www.pnas.org/content/early/2019/10/11/1820846116.abstract

90. Snyder-Mackler N, Sanz J, Kohn JN, Voyles T, Pique-Regi R, Wilson ME, et al. Social status alters chromatin accessibility and the gene regulatory response to glucocorticoid stimulation in rhesus macaques. Proc Natl Acad Sci U S A [Internet]. 2019;116(4):1219_ 28. Available from:

http://www.ncbi.nlm.nih.gov/pubmed/30538209\%0Ahttp://www.pubmedcentral.nih.gov/arti clerender.fcgi?artid=PMC6347725

91. Snyder-Mackler N, Sanz J, Kohn JN, Brinkworth JF, Morrow S, Shaver AO, et al. Social status alters immune regulation and response to infection in macaques. Science (80- ) [Internet]. 2016 Nov 25;354(6315):1041 LP - 1045. Available from: http://science.sciencemag.org/content/354/6315/1041.abstract

92. Bartolomucci A. Social stress, immune functions and disease in rodents. Front Neuroendocrinol. 2007;28(1):28-49.

93. Tung J, Barreiro LB, Johnson ZP, Hansen KD, Michopoulos V, Toufexis D, et al. Social 
environment is associated with gene regulatory variation in the rhesus macaque immune system. Proc Natl Acad Sci [Internet]. 2012 Apr 24;109(17):6490 LP - 6495. Available from: http://www.pnas.org/content/109/17/6490.abstract

94. Stringhini S, Polidoro S, Sacerdote C, Kelly RS, Van Veldhoven K, Agnoli C, et al. Lifecourse socioeconomic status and DNA methylation of genes regulating inflammation. Int J Epidemiol. 2015;44(4):1320-30.

95. Miller GE, Chen E, Fok AK, Walker H, Lim A, Nicholls EF, et al. Low early-life social class leaves a biological residue manifested by decreased glucocorticoid and increased proinflammatory signaling. Proc Natl Acad Sci [Internet]. 2009 Aug 25;106(34):1471621. Available from: http://www.pnas.org/content/106/34/14716.abstract

96. Powell ND, Sloan EK, Bailey MT, Arevalo JMG, Miller GE, Chen E, et al. Social stress up-regulates inflammatory gene expression in the leukocyte transcriptome via $\beta$ adrenergic induction of myelopoiesis. Proc Natl Acad Sci. 2013;110(41):16574-9.

97. Cole SW, Conti G, Arevalo JMG, Ruggiero AM, Heckman JJ, Suomi SJ. Transcriptional modulation of the developing immune system by early life social adversity. Proc Natl Acad Sci. 2012;109(50):20578-83.

98. Thames AD, Irwin MR, Breen EC, Cole SW. Experienced discrimination and racial differences in leukocyte gene expression. Psychoneuroendocrinology. 2019;106:277-83.

99. Qin D-D, Rizak JD, Feng X-L, Chu X-X, Yang S-C, Li C-L, et al. Social rank and cortisol among female rhesus macaques (Macaca mulatta). 2013;

100. Hausfater G. Dominance and reproduction in Baboons (Papio cynocephalus). Contrib Primatol. 1975;7:1-150.

101. Rosenbaum S, Zeng S, Campos FA, Gesquiere LR, Altmann J, Alberts SC, et al. Social bonds do not mediate the relationship between early adversity and adult glucocorticoids in wild baboons. Proc Natl Acad Sci. 2020;117(33):20052-62.

102. Resende LS, Amaral CE, Soares RBS, Alves AS, Alves-Dos-Santos L, Britto LRG, et al. Social stress in adolescents induces depression and brain-region-specific modulation of the transcription factor MAX. TransI Psychiatry. 2016;6(10):e914-e914.

103. Picard M, McEwen BS, Epel ES, Sandi C. An energetic view of stress: focus on mitochondria. Front Neuroendocrinol. 2018;49:72-85.

104. Alberts SC, Altmann J. The Amboseli Baboon Research Project: 40 years of continuity and change. In: Long-term field studies of primates. Springer; 2012. p. 261-87.

105. Wall JD, Schlebusch SA, Alberts SC, Cox LA, Snyder-Mackler N, Nevonen KA, et al. Genomewide ancestry and divergence patterns from low-coverage sequencing data reveal a complex history of admixture in wild baboons. Mol Ecol. 2016;25(14):3469-83.

106. Tung J, Zhou X, Alberts SC, Stephens M, Gilad Y. The genetic architecture of gene expression levels in wild baboons. Elife. 2015;4:e04729\%@ 2050-084X.

107. Altmann J, Alberts SC, Haines SA, Dubach J, Muruthi P, Coote T, et al. Behavior predicts genes structure in a wild primate group. Proc Natl Acad Sci. 1996;93(12):5797-801.

108. Buenrostro JD, Giresi PG, Zaba LC, Chang HY, Greenleaf WJ. Transposition of native chromatin for fast and sensitive epigenomic profiling of open chromatin, DNA-binding proteins and nucleosome position. Nat Methods. 2013;10(12):1213.

109. Altmann J. Observational study of behavior: sampling methods. Behaviour. 1974;49(34):227-66.

110. Levy EJ, Zipple MN, McLean E, Campos FA, Dasari M, Fogel AS, et al. A comparison of dominance rank metrics reveals multiple competitive landscapes in an animal society. Proc R Soc B. 2020;287(1934):20201013.

111. Strauss ED, Holekamp KE. Inferring longitudinal hierarchies: Framework and methods for studying the dynamics of dominance. J Anim Ecol. 2019;88(4):521-36.

112. Dobin A, Gingeras TR. Mapping RNA-seq Reads with STAR. Curr Protoc Bioinforma [Internet]. 2015 Sep 1;51(1):11.14.1-11.14.19. Available from: 
https://doi.org/10.1002/0471250953.bi1114s51

113. Batra SS, Levy-Sakin M, Robinson J, Guillory J, Durinck S, Vilgalys TP, et al. Accurate assembly of the olive baboon (Papio anubis) genome using long-read and $\mathrm{Hi}-\mathrm{C}$ data. Gigascience. 2020;9(12):giaa134.

114. Anders S, Pyl PT, Huber W. HTSeq-a Python framework to work with high-throughput sequencing data. Bioinformatics. 2015;31(2):166-9.

115. Li H. Aligning sequence reads, clone sequences and assembly contigs with BWA-MEM. arXiv Prepr arXiv13033997. 2013;

116. Zhang Y, Liu T, Meyer CA, Eeckhoute J, Johnson DS, Bernstein BE, et al. Model-based analysis of ChIP-Seq (MACS). Genome Biol. 2008;9(9):1-9.

117. Law CW, Chen Y, Shi W, Smyth GK. voom: Precision weights unlock linear model analysis tools for RNA-seq read counts. Genome Biol [Internet]. 2014;15(2):R29.

Available from:

http://www.ncbi.nlm.nih.gov/pubmed/24485249\%0Ahttp://www.pubmedcentral.nih.gov/arti clerender.fcgi?artid=PMC4053721

118. Ritchie ME, Phipson B, Wu DI, Hu Y, Law CW, Shi W, et al. limma powers differential expression analyses for RNA-sequencing and microarray studies. Nucleic Acids Res. 2015;43(7):e47-e47.

119. Akdemir D, Okeke UG. EMMREML: Fitting mixed models with known covariance structures. R Packag version. 2015;3(1).

120. Poplin R, Ruano-Rubio V, DePristo MA, Fennell TJ, Carneiro MO, Van der Auwera GA, et al. Scaling accurate genetic variant discovery to tens of thousands of samples. BioRxiv. 2018;201178.

121. Dabney A, Storey JD, Warnes GR. qvalue: $Q$-value estimation for false discovery rate control. R Packag version. 2010;1(0).

122. Subramanian A, Tamayo P, Mootha VK, Mukherjee S, Ebert BL, Gillette MA, et al. Gene set enrichment analysis: a knowledge-based approach for interpreting genome-wide expression profiles. Proc Natl Acad Sci. 2005;102(43):15545-50.

123. Team RC. R: A language and environment for statistical computing. 2013;

124. Friedman J, Hastie T, Tibshirani R. Regularization paths for generalized linear models via coordinate descent. J Stat Softw. 2010;33(1):1.

125. Heinz S, Benner C, Spann N, Bertolino E, Lin YC, Laslo P, et al. Simple combinations of lineage-determining transcription factors prime cis-regulatory elements required for macrophage and B cell identities. Mol Cell. 2010;38(4):576-89. 